ISSN: 0212-5099

DOI: https://doi.org/10.24310/BAETICA.2018.v0i38.5521

\title{
LA PROMOCIÓN DEL CULTO EUCARÍSTICO COMO ARMA PARA COMBATIR A LOS MORISCOS: NOTAS PARA SU ESTUDIO EN EL ANTIGUO REINO DE GRANADA
}

\author{
JAVIER GonzÁlez TORRes* \\ Fundación Victoria - Universidad de Málaga
}

\section{RESUMEN}

En los últimos tiempos, numerosos estudios han puesto de relieve los enfrentamientos protagonizados en el sur peninsular por dos significativos pueblos: los cristianos y los moriscos; investigaciones que han ahondado en sus antagonismos, interpretado normativas políticas y reconstruido movimientos conspiratorios tendentes a la defensa de diversas particularidades.

Para completar esa visión de conjunto, proponemos centrar la atención en el estamento eclesiástico. En paralelo al poder civil, implementa un programa catequético hacia los moriscos poniendo en valor elementos consustanciales; entre ellos destaca el culto y veneración al sacramento de la Eucaristía, convertido en poderosa y simbólica arma frente al credo y costumbres islámicas. Éstas, pese a los esfuerzos, seguirán latentes.

PALABRAS-CLAVE: Península Ibérica, culto eucarístico, enfrentamiento religioso, moriscos, evangelización

*javier.gonzalez@fundacionvictoria.edu.es ORCID: http://orcid.org/0000-0001-9983-6657

(C) Baetica. Estudios Historia Moderna y Contemporánea, 38, 2018, 79-113. Facultad de Filosofía y Letras, Universidad de Málaga. Departamento de Historia Moderna y Contemporánea 
ISSN: 0212-5099

DOI: https://doi.org/10.24310/BAETICA.2018.v0i38.5521

\title{
THE SIGNIFICANCE OF THE EUCHARIST VENERATION AS A COMBAT WEAPON AGAINST THE MORISCOS: NOTES FOR A STUDY IN THE FORMER KINGDOM OF GRANADA
}

\author{
JaVier GonzÁlez Torres* \\ Fundación Victoria - Universidad de Málaga
}

\begin{abstract}
In recent years, many studies have focused on confrontations in the south of the Península between two significant civilizations: the cristianos and the moriscos; investigations that have deepened their antagonisms, interpreted political norms and reconstructed conspiratorial movements tending to the defense of diverse particularities.

To complete this overview, we propose to focus attention on the ecclesiastical establishment. In parallel to the civil power, the Church implements a program of catechetical adhesión of the moriscos, putting in value its most consubstantial elements; among them stands out the cult and veneration to the sacrament of the Eucharist, turned into powerful and symbolic weapon against the Islamic creed and customs.
\end{abstract}

KEY WORDS: Iberian peninsula, Eucharistic cult, religious confrontation, moriscos, evangelism

*javier.gonzalez@fundacionvictoria.edu.es

ORCID: http://orcid.org/0000-0001-9983-6657

(C) Baetica. Estudios Historia Moderna y Contemporánea, 38, 2018, 79-113.

Facultad de Filosofia y Letras, Universidad de Málaga. Departamento de Historia Moderna y Contemporánea 
1492-1610. En los ciento dieciocho años que separan ambas fechas, las generaciones moriscas del antiguo reino de Granada viven momentos convulsos. Desde que la capital pasara a manos de los cristianos, las prácticas islámicas siguen vigentes a pesar de las conversiones masivas realizadas a comienzos del siglo XVI.

Las decisiones políticas tomadas por los diferentes monarcas encontrarán eco en diversas actuaciones eclesiásticas. Será el clero quien desarrolle un ambicioso programa de evangelización en la costa oriental andaluza, convirtiéndose sus diócesis en precursoras del culto eucarístico. Así, desde el terreno pastoral, se conforma un poder paralelo capaz de argumentar razones que conviertan el sacramento en doble arma de combate: de un lado, contra las creencias islámicas; $\mathrm{y}$, de otro, en sustento esencial para una conversión más efectiva.

\section{LOS MORISCOS Y SU COMPLEJO ENCAJE SOCIAL. LA CONTEXTUALIZACIÓN DE UN PROBLEMA}

Si las Capitulaciones plantearon relaciones basadas en el respeto muto y coexistencia pacífica, la nueva centuria trae consigo un cambio de mentalidad: control absoluto, discriminación étnica y rechazo racial. Atrás queda la concordia entre los Reyes Católicos y el último monarca nazarí cuando el cardenal Cisneros ordena, en febrero de 1502, el requisamiento de las colecciones de libros árabes existentes en Granada y su posterior quema ${ }^{1}$, dictando la conversión forzosa de la comunidad musulmana.

Las causas de este cambio se deben a una cuestión política: el Estado en ciernes y la Iglesia conforman una unidad insoslayable. A partir de ahí, la dos opciones que se plantea a todo habitante con pasado islámico es clara: bautismo o expulsión. Y bajo tales cuestiones comienza la 'cristianización' de neo-catecúmenos. Proyecto que, además, convierte a los reinos hispanos en modelo para las monarquías europeas, liderando así la 'antigua cruzada' que los enfrentaba a los turcos en el Mediterráneo y que situará a Carlos I como un monarca implacable ${ }^{2}$.

1. Narración recogida por A. DE LA TORRE (1913), 35.

2. Una imagen exterior que choca con algunas de las decisiones tomadas en política interior. Por ejemplo, en 1526 el rey deja sin efecto -durante cuarenta años-, las ordenanzas que obligaban a los moriscos a abandonar su forma de vida y a insertarse en la comunidad cristiana. Tal determinación motivaría una etapa de distensión con las 
Pasada la fase de las conversiones forzosas y entendiendo que las consecuencias de tales acciones coercitivas conllevaban más perjuicios que beneficios ${ }^{3}$, llegado el primer tercio de la centuria se opta por una actitud más conciliadora. En esta queda sobreentendido que la minoría étnica necesita tiempo para adaptarse al cristianismo y, por supuesto, asimilar su mensaje. Incluso la Inquisición, en aplicación de las directrices de la Congregación de la Capilla Real, opta a partir de 1526 por procesar solo a quienes celebren ceremonias islámicas, no siendo necesaria la abjuración pública de sus antiguas creencias como tampoco se procede a la confiscación de bienes. Es más, en 1543 se sientan las bases para una nueva concordia con el Santo Oficio, pero el rechazo recibido tanto por el Tribunal como del papado, hacen que fracase.

Con el paso de las décadas, las autoridades irán optando por medidas más aculturadoras, como la represión selectiva y drástica pérdida de las señas de identidad de lo morisco. Así, el reinado de Felipe II se corresponde con un nuevo giro que no solo afecta al enquistado problema sino a otros que discurren en paralelo ${ }^{4}$. La "definitiva" solución a la cuestión llegará con Felipe III y el conocido decreto de expulsión de 1609-1610.

El contexto cultural en el que se desenvuelven estas etapas discurre en paralelo a la proyección, en un primer momento, de ideas humanistas y, posteriormente, de la paulatina implementación de las pautas del Concilio de Trento. Ambas corrientes otorgan matices diferenciadores a las decisiones político-religiosas y conllevan puntos de vista que las condicionan. Y es que la reforma del estamento eclesiástico español comienza a llevarse a cabo antes que en otros países europeos. El movimiento es fruto de una reflexión particular que lleva a plantear la toma de decisiones drásticas con tal de poner coto a diferentes cuestiones y a reordenar, sistemáticamente, la Iglesia particular. Es por ello que el episcopado español, formado desde las décadas iniciales del siglo XVI en las universidades de Salamanca y Alcalá, inicia un camino de renovación que sirve de laboratorio de pruebas para ulteriores proyectos. Así, la Reforma católica que deriva de la aplicación de los acuerdos de Trento estará precedida de los ensayos llevados a

generaciones de nazaríes que siguieron a las bautizadas en las primeras campañas. De hecho, este sacramento era el único que se mantendría como obligatorio.

3. Entre otras cuestiones porque se llevan a cabo de manera masiva, sin recibir una conveniente catequización. La minoría, por su parte, claudica ante tal ceremonial con la idea de no perder sus posesiones, así como mantener sus oficios y situación fiscal. Cfr. M. A. Ladero Quesada (1988).

4. Vide B. de Atienza y A. de Angulo (1569), 147. 
cabo en las diócesis peninsulares ${ }^{5}$ las cuales, de por sí, aportan al debate conciliar a destacados teólogos ${ }^{6}$.

En este sentido, es crucial el proceso de formación del clero hispano. A pesar de las complicaciones propias del momento histórico, en las notables aulas universitarias españolas se implanta un equilibrado programa de estudios donde la formación clásica se proyecta en paralelo con la teología, el conocimiento bíblico se relaciona con el positivismo y el análisis especulativo, al tiempo que la ciencia sagrada no rompe con la ingente escolástica medieval. Estos aspectos serán aplicados con posterioridad en otras instituciones europeas y, en muchos casos, de la mano de docentes españoles.

De ahí que el estudio de las fuentes primarias, la observación pormenorizada de la actualidad y el uso de una exposición sencilla deriva en la implantación de una exégesis analítica centrada en los dogmas y en su aplicación para combatir críticas, disidencias o problemas. Una de las consecuencias de esta implantación se proyecta en el complejo terreno de la educación de los fieles, a los cuales se les conmina a ejercer la oración como instrumento personal de comunicación con la divinidad, así como a ejercitar prácticas devotas. Será este aspecto uno de los propósitos de la pastoral más cercana, ejercida tanto por el clero como por las propias órdenes mendicantes y proyectada hacia el terreno de la religiosidad local. Junto a la predicación en sí, la promoción del asociacionismo resulta clave para concretar rituales comunitarios que requieren a su vez de otros elementos de naturaleza artística.

La conjugación de todas estas premisas suponen el aporte teórico fundamental a partir del cual tienen lugar en las antiguas coras nazaríes, iniciativas cultuales que difunden la devoción a la Eucaristía y proyectan su culto cual vía expresiva que cumpla un doble objetivo: demostrar el dogma cristiano para, con ello, exterminar la práctica islámica y, a su vez, evangelizar a la sociedad bajo criterios incuestionables. La revisión de esa vida sacramental que a partir de entonces debe guiar el devenir de los fieles -tanto adultos como niños y jóvenes- es la base fundamental sobre la que se tomarán importantes decisiones que afectarán, por igual, a los

5. Prueba de ello es la celebración de sínodos diocesanos, anteriores a los dictaminados obligatoriamente por las actas trentinas. Al respecto, entre 1475 y 1558 , se contabilizan alrededor de 150 .

6. Se trata esta de una idea defendida por la historiografía contemporánea a partir de fundamentos teóricos demostrables. Como ejemplo, véase A. Fernández Collado (2007), 38-39. 
miembros de la comunidad cristiana. Si en estos, además, surgen recelos o rechazos, el 'peso' teórico del dogma deberá prevalecer por encima de tales opiniones, ahondándose en su trascendencia y necesidad.

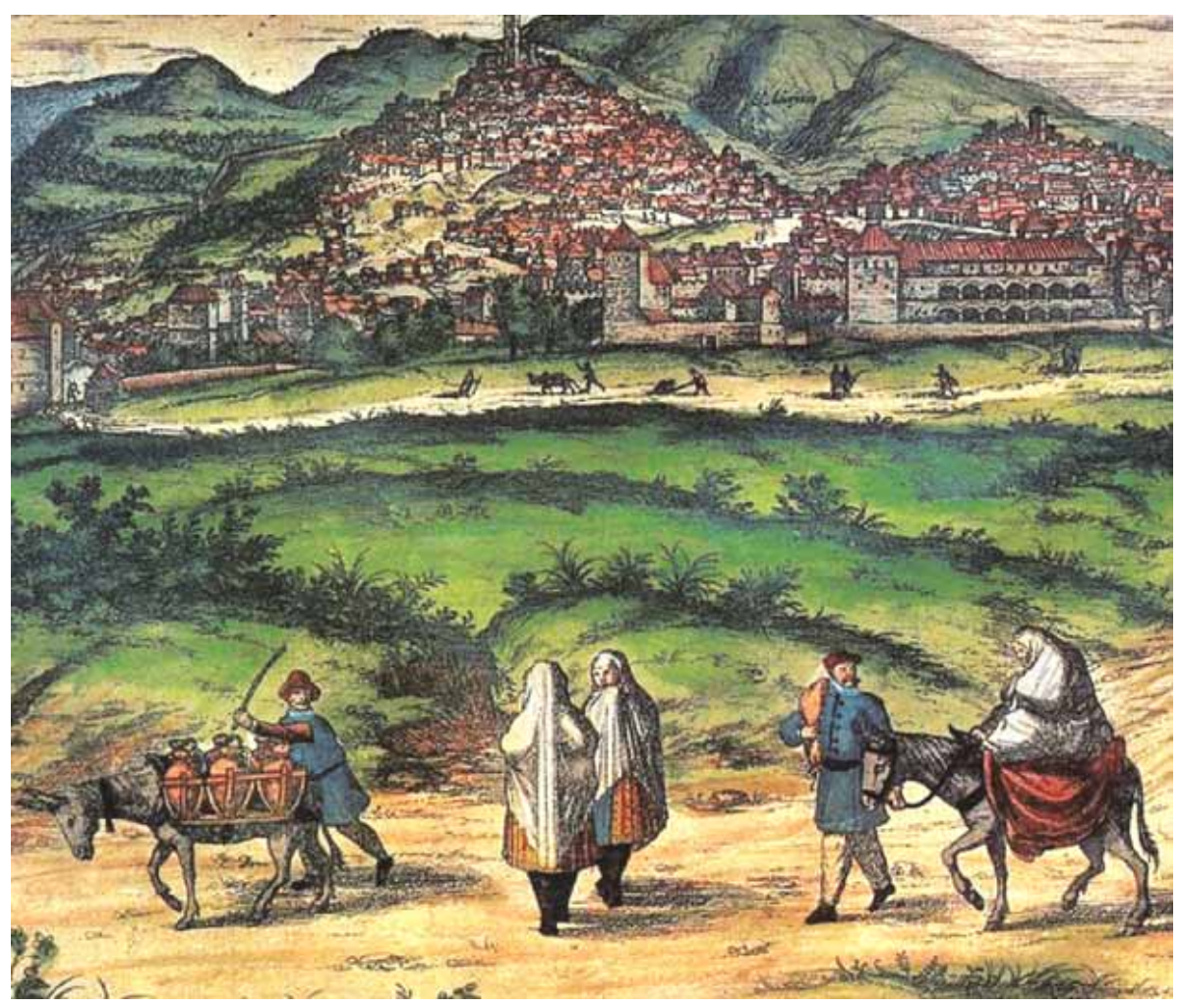

Imagen 1. Joris Hoefnagel (1565). Visión de Granada con los moriscos de la Vega en primer término. 


\section{EL CULTO EUCARÍSTICO, UNA RAZÓN MÁS PARA LA LUCHA CONTRA LOS MORISCOS}

A pesar de la existencia de numerosa bibliografía que estudia todo este proceso de convivencia forzosa, hasta la fecha no se ha realizado una investigación transversal y lineal donde el culto eucarístico se entienda cual método de control grupal y de superposición espiritual/moral frente a la antigua sociedad musulmana.

El caso es que tal cuestión constituye un aspecto que, sumado a otros de raíz político-social, convergen hacia la misma línea coercitiva y dominadora comentada, completando y dando solución a iniciativas tomadas desde ámbitos alejados de lo eclesiástico. De ahí la necesidad de, al menos, sentar las bases historiográficas para elaborar un próximo "estudio de caso" mucho más profundo que venga a solventar ciertas lagunas historiográficas.

En este sentido, cobra vital importancia el referido proceso de reforma eclesiástica española que, en ocasiones concretas, pueden estar en línea con las intenciones del poder político. De hecho, tras el establecimiento del programa de estudios y la difusión de las ideas renovadas tanto hacia el clero como al conjunto de las órdenes existentes en España, el paso siguiente será la depuración de la vida religiosa de los fieles; todo pasa por la reactivación de los sacramentos que históricamente enraízan con la esencia misma del hecho eclesial. Así y en primer lugar, cobra importancia el Bautismo, ceremonia iniciática que marca al catecúmeno como nuevo miembro comunitario; un signo indeleble con consecuencias inmediatas para el futuro de esa persona que, con independencia de su edad, comienza una nueva etapa personal que culminará en la muerte tras la recepción de los sacramentos de la penitencia y la unción de enfermos7. Ese "viaje" existencial debe estar espiritualmente supervisado por el clero que, de igual manera, preparará el alma del pecador para el tránsito definitivo hasta el cielo, superando tentaciones a partir de la confianza en la misericordia divina y en los méritos de la pasión de Cristo ${ }^{8}$.

En última instancia y siguiendo la secuencia temporal descrita, el sacramento que da sentido a toda esa vivencia particular es la Eucaristía.

7. No es este último sacramento de uso frecuente en el siglo XVI debido a teorías supersticiosas creadas tiempo atrás, no siendo capaz la reforma española de abandonarlas y, por ende, superarlas con prontitud.

8. Los libros del Ars moriendi son esclarecedores del tránsito experiencial que convidan al fiel a participar de los sacramentos para así prepararse, llegado el momento, para la muerte y el perdón de sus pecados. 
Es un signo que recuerda al fiel su particular adhesión a la Iglesia y su sintonía personal con Cristo, cuyo memorial de redención revive cada vez que comulga el pan y el vino. El aumento de la devoción eucarística y la recepción asidua de la comunión encuentran en este tiempo una dimensión extraordinaria, amparada en una doble vía: la intelectual, en la que tienen cabida las directrices jurídico-litúrgicas que dimanan de extensos debates teológicos; y, la popular, a través de la predicación y la praxis devota.

Ante tales cuestiones, ¿qué opina un morisco, convertido a una creencia diferente a la heredada, sin apenas preparación? La respuesta es evidente y mayoritaria: rechazo absoluto. Para ellos, la Iglesia es una institución que monopoliza el Evangelio y lo reinterpreta de manera subjetiva ${ }^{9}$. Por lo tanto, al no tener conciencia de estar en pecado, rechaza explícitamente el bautismo, la penitencia y la Eucaristía. El primer sacramento es un acto simbólico; del segundo no entienden cómo Dios puede ser sustituido por un hombre -igualmente pecador-, capaz de dilucidar la gravedad de lo sucedido e imponer una "pena"; y, con respecto al tercero, el proceso transustanciador es incomprensible.

De ahí que, cuando acuden a misa, se den la vuelta cuando se alza la hostia consagrada, se escondan o se duerman, no acudiendo a la comunión. Las dudas sobre la confección del pan, atribuida al sacristán parroquial, les permite opinar sobre la imposibilidad de que el hijo de Dios esté presente en la misma. Y cuando el viático se lleva a los enfermos, no adoptan una postura acorde con tan significativa presencia, renegando sin ambages sobre la misma o cambiando de calle. De hecho, el poder salvífico de la hostia consagrada es puesto en solfa por parte de alguno de ellos, prefiriendo que se les diese a las bestias de carga enfermas antes que a ellos ${ }^{10}$.

La literatura aljamiada, incluso, va más allá: "el disparate que los christianos diçen es que en la ostia está su Dios, y con tener ellos por fe de que está en ella, se la tragan, echando tras ella un trago de vino, y todo revuelto lo echan por la bía de la çuidad"11. Y frente a tan atroces cuestiones, apostarían por la taqiyya, la resistencia vital ante el poder coercitivo de los contrarios, manteniendo sus creencias y hábitos de vida.

9. R. Benítez Sánchez-Blanco y E. Císcar Pallarés (1979), 255-310.

10. Opiniones recopiladas por cronistas de la época o recogidas en procesos jurídicoreligiosos. Vide los casos conquenses trabajados por M. García-Arenal (1978), 105.

11. Manuscrito anónimo (siglo XVII) titulado Artículos de la Ley mahometana y explicación de ella en castellano. Biblioteca Nacional de España MSS/9654. 
No es de extrañar que incluso los propios religiosos expongan opiniones contrarias a tal proceder, definiendo actitudes moriscas en el sentido que "nacían con la mentira en la boca: y siempre procuravan engañar al Christiano. [...] Creyan que bastava para borrar [...] el Bautismo, era limpiarle la cabeça al niño después de bautizado con un paño mojado, o con una migaja de pan"12. No fue esta una aseveración compartida por otros eclesiásticos, como los jesuitas. Estos incluso desarrollaron una interesante experiencia de predicación y enseñanza hacia los moriscos en zonas rurales granadinas ${ }^{13}$.

De todo ello se colige la necesidad de establecer una serie de pautas generales capaces de hacer ver la vital significación que para la vida cristiana tienen los sacramentos y, de todo ellos especialmente, el de la eucaristía. Será éste pues uno de los motivos fundamentales de una novedosa acción eclesial.

\section{LAS DIMENSIONES DEL PROYECTO COMÚN: NORMATIVA, LITURGIA Y CULTO}

Surgen así tres vías esenciales para el desarrollo del objetivo expuesto, argumentadas en pro de intensificar la pedagogía ante la creciente incomprensión. Entre ellas existen interesantes conexiones y derivaciones pues, no en vano, parten de un catolicismo militante que pretende envolver el misterio sacramental en la fuerza centrípeta de la jurisprudencia, la vivencia experiencial de la liturgia y la acción catequética del culto.

\subsection{Las Constituciones sinodales y la literatura doctrinal, entre el marco jurídico y la popularización de un ideal}

Las Constituciones sidonales establecen el gobierno diocesano y programan actuaciones de diversa genealogía. Su incidencia sobre la realidad social las convierten en testimonio de situaciones concretas; incluso, como su contenido es más disciplinar que normativo, se coligen interesantes cuestiones argumentadas en pro de corregir aberraciones jurídico-administrativas, litúrgicas o ético-morales ${ }^{14}$. De tal manera, los textos que dimanan de las diócesis del

12. J. Bleda (1618), 952.

13. Vide la actividad de Ignacio de las Casas, antiguo musulmán, en Y. El Alaoui (1997), 317-339.

14. Las cuestiones relativas al desarrollo de estas convocatorias y su especial incidencia en la vida sacramental andaluza están extraídas de J. GonzÁlez Torres (2017). 
antiguo reino de Granada suponen de por sí un espejo en el que se reflejan de manera prístina los problemas de cada una de ellas, siendo el de los moriscos un aspecto clave $\mathrm{e}^{15}$.

En fecha temprana y desde el arzobispado de Sevilla, se hace una primera mención. El Concilio provincial de 1512 marca una serie de pautas en relación a las dificultades que una sociedad multiétnica puede tener en pro de la asimilación de ideas concretas:

Habiendo en nuestra diócesis y provincia muchos recién conversos de la ley judaica y de la secta mahometana $[\ldots]$ establecemos y ordenamos $[\ldots]$ que los prelados $[\ldots]$ nombren personas honestas y doctas que los intruyan en todo lo necesario a su salvación.

Tales observaciones tienen su paralelismo en las acciones evangelizadoras que ejercen los obispos de Málaga, Granada y Almería en esa misma década, preocupados por cómo los moriscos aceptarían las conversiones sin estar debidamente preparados. Así lo hace saber en 1512 el prelado malagueño Diego Ramírez de Villaescusa, entendiendo que el rápido proceso requiere de algunas "reglas y constituciones para que mejor sea dios servido y su culto augmentado"16. En este sentido, las Ordenanzas de Huéscar y Castilléjar, de 1514, hacen obligatoria la asistencia a misa para los 'cristianos nuevos', -todos sin exclusión, fuesen hombres o mujeres- para, una vez terminada, formarse en doctrina catequética ${ }^{17}$. Una línea a la que también contribuyen las órdenes mendicantes, iniciando una labor proselitista más activa en el ámbito urbano: campañas diversas, apertura de centros de enseñanza y exteriorización de cultos significativos.

Como ya se ha apuntado, las costumbres se relajaron y no será hasta mediados de siglo cuando se produzca un viraje hacia una menor intransigencia. A ello responde el sínodo de Guadix y Baza presidido por el obispo, Martín Pérez de Ayala, a comienzos de $1554^{18}$. La convocatoria sirve para

15. Es interesante conocer como, desde la óptica historiográfica de la época, la opinión que se tiene de la minoría morisca resulta fundamental a la hora de estudiar, relacionar y analizar todos aquellos aspectos que rodean el controvertido marco contextual objeto de este estudio. Una reciente aportación crítica sobre la obra del historiador Luís del Mármol Carvajal la ofrece J. CAstillo Fernández (2013).

16. D. Ramírez de Villaescusa de Haro (1512?), s/f.

17. De no hacerlo, se les impondría un sanción económica. Vide A. Gallego Burín y A. Gámir Sandoval (1968), pp. 182-184.

18. Teólogo giennense (1504-1566), estudió en Salamanca y Alcalá, ejerciendo de catedrático de Filosofía y Teología en Granada. Prelado de Guadix (1548-1560), Segovia 
paliar las carencias detectadas durante las visitas canónico-pastorales y que merecen, por su gravedad, de una respuesta contundente; entre ellas, los moriscos que, por distintas circunstancias, mantienen sus cultos y cultura, habiéndose hecho con el control de buena parte de la economía accitana y bastetana $^{19}$. Además se les acusa de instigar altercados en templos, desarrollando actitudes desafiantes y blasfemas contra el sacramento ${ }^{20}$.

Así, en las Sinodales, estas corruptelas son entendidas como comportamientos desviados de las normas, proponiéndose medidas para su corrección. El texto revela el interés del prelado por sistematizar la organización diocesana y establecer cuantos criterios fueran menester con tal de argumentar la autoridad de la Iglesia sobre sus miembros, con independencia de su origen, a partir de una sobriedad conceptual encomiable aprehendida en las sesiones del Trentino. Se trata de asentar una formación rigurosa, tanto del clero como de los fieles, para construir los cimientos de un obispado en sintonía con la Devotio moderna.

En este sentido, el culto eucarístico se reviste de la pomposidad conceptual y erudita formulación que emana directamente del Concilio. Al respecto se establece el procedimiento litúrgico-espiritual adecuado para impartir la comunión, en la que deben participar todos los fieles "con temor y reverencia, y dolor de sus peccados: porque el sancto combite del altar les pueda ser provechoso"21. A partir de tales premisas introductorias, se define la importancia sacramental de la Eucaristía, ordenando

(1560-1564) y Valencia (1564-1566), participa por petición expresa de Carlos I en los Coloquios de Worms y Ratisbona, tras su nombramiento como capellán imperial, así como en el Concilio de Trento; en este, interviene en las comisiones que elaboran los cánones sobre la Eucaristía, la penitencia y la unción de enfermos.

19. Con el propósito de no ver alterado tal status, la concordia fiscal firmada por la Corona les permite realizar aportaciones económicas para el mantenimiento de la Corona. La bibliografía al respecto es amplia, destacando las aportaciones sobre fiscalidad y pactos políticos firmados por el prof. A. Galán Sánchez; en esas relaciones, destacan igualmente el rol jugado por determinadas familias castellanas en aras de mediar en el conflicto y vigilar el cumplimiento de lo acordado, como ocurre con los Mendoza (vide los diversos estudios del prof. A. Jiménez Estrella).

20. P. SuÁrez (1696) p. 187 y ss. El memorial de escándalos no se circunscribe únicamente a recintos sacros; en un interés por hiperbolizar en pleno Barroco distintos comportamientos amorales, se citan abusos sexuales en cementerios, celebración de orgías la primera noche del verano, verificación de extraños rituales medicinales, atavío de ciertas mujeres o ceremonias matrimoniales en las que se hacían profecías para el advenimiento de un nuevo al-Ándalus.

21. M. Pérez de Ayala (1556), XIVa.

(C) Baetica. Estudios Historia Moderna y Contemporánea, 38, 2018, 79-113. Facultad de Filosofía y Letras, Universidad de Málaga. Departamento de Historia Moderna y Contemporánea 
la disposición de sagrarios o repositorios para la custodia de las especies consagradas en el centro de los retablos mayores de las parroquias, "con toda decencia"22.

La línea argumental va adecuándose a las especiales circunstancias que se viven en la diócesis a medida que avanzan las Sinodales, con tal de modificar ciertos hábitos y poner el acento sobre otros más trascendentes. Así, llegado el punto dedicado al día del Corpus Christi, la normativa comienza recomendado a los diocesanos:

honrrar y venerar el sanctissimo sacramento del altar, prenda inextimable de nuestra redempcion, especialmente en los tiempos de ahora, en que (por nuestros peccados) ay tantos errores y heregias sembradas en la Yglesia de Dios nuestro señor, contra algunas verdades catholicas concernientes a el, y porque en estas ciudades de Guadix y Baça, donde ay copia de gente principal y Christianos viejos, suele salir el sancto sacramento algo desacompañado de cleregia, y no con aquella decencia y autoridad que conviene ${ }^{23}$.

Continúa la instrucción haciendo un llamamiento a la participación responsable ${ }^{24}$ a la Misa mayor y posterior procesión, invitando a las parroquias cercanas a Guadix a acudir con cruz procesional propia y beneficiado. Basta recordar que dicha festividad "es principalissima y de gran solemnidad" 25 , ordenándose su celebración con las puertas de los templos abiertas y tañendo campanas, al tiempo que se vigile que al paso del cortejo ningún fiel realice blasfemia alguna. Al respecto de ello, así como del comportamiento durante otros servicios religiosos, se dedica el Título sexto de las Sinodales, argumentando "la falta de religión que avemos visto en los nuevos christianos [...] quando están presentes al tremendo misterio de la Missa"26. Para una adecuada actitud, se responsabiliza a los sacerdotes, quienes deben explicar a los fieles -en especial,

22. Ibidem, XVa.

23. Ibidem, XVIIIr-XXIXa

24. Se trata de poner freno al comportamiento poco adecuado de los célibes en el cortejo así como ordenar a sus integrantes, imponiendo sanciones económicas al incumplimiento de esta normativa y de los Estatutos tanto de la Catedral accitana como de la Colegiata bastetana.

25. M. Pérez de Ayala (1556), XXIXr.

26. Ibidem, LIa. Más adelante se indica que se ponga atención en detectar casos concretos que contravienen las costumbres, por ejemplo: "no mirar hacia el altar ni adorar la sancta hostia quando la alçan". 
a los moriscos- cómo deben actuar ante determinados momentos del culto $^{27}$.
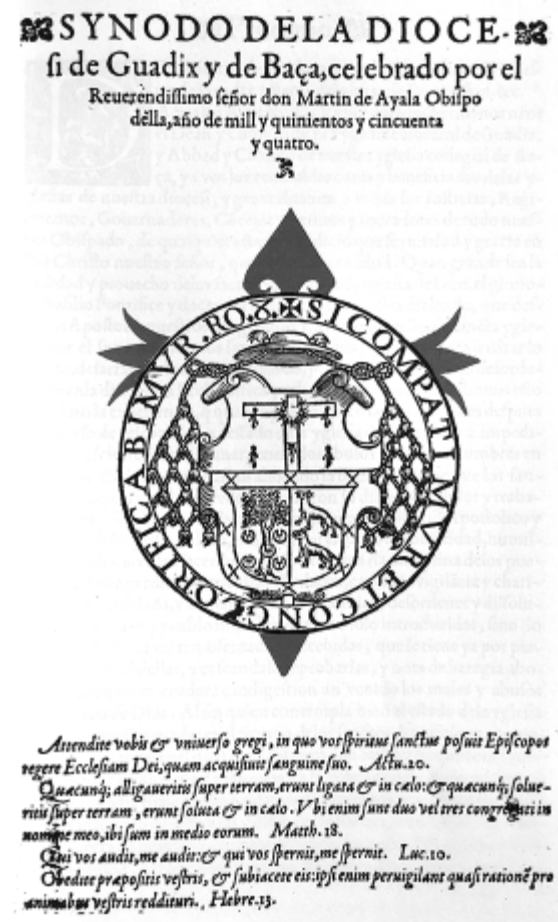

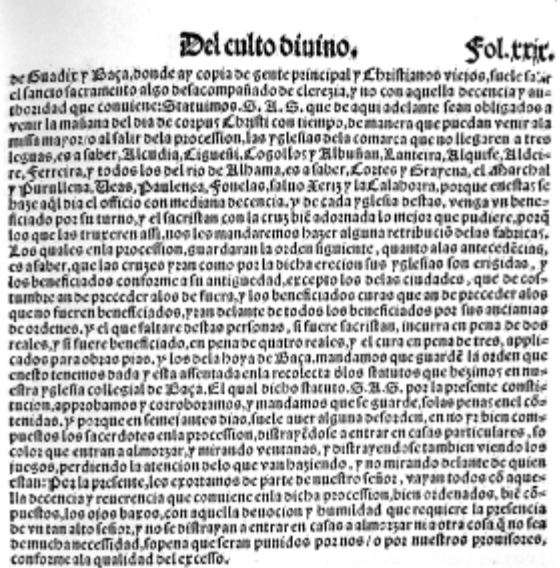
conforescata qualididad oclercelio.

TConftitucion.rxi. Que feă obligadog a venír ala p2o:

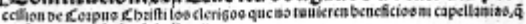

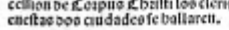
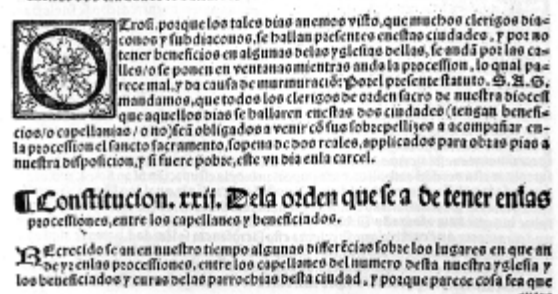

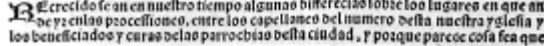
citre

Imagen 2. Frontispicio y folio XXIX (anverso) de las Constituciones sinodales de Guadix de 1545.

El impacto que tan sustanciosa ordenación canónica realiza en Guadix, apenas sin dejar resquicio legal alguno a posibles interpretaciones, debió suponer para el resto de las diócesis del antiguo Reino un impulso a tomar medidas similares toda vez que la problemática morisca presentaba similares circunstancias. Así ocurre con el sínodo

27. Con especial indicación de la asistencia semanal -incluyendo controles y penas en caso de ausencias - a la Eucaristía dominical, a la que deben acudir "con atención, devoción y silencio, teniendo los ojos del alma puestos en aquel admirable misterio de la passion de Jesu Christo nuestro redemptor que en la venerada missa al vivo se representa". Ibidem, LIa, LIr. 
provincial de Granada, celebrado en 1565, convocado por el arzobispo Pedro Guerrero ${ }^{28}$.

Su celebración está ligada, a su vez, a la finalización del concilio de Trento. Suelen repetir las fuentes del momento que el papa Pío IV afeó al término de la sesión final al arzobispo ser el pastor de la diócesis menos cristiana de todo el orbe católico, en clara referencia a los moriscos, encargándole expresamente "que dixese de su parte al Rey Don Felipe nuestro señor, que pusiese remedio como aquellas almas no se perdiesen" ${ }^{29}$. De ahí la convocatoria de un sínodo, en cuyo trasfondo debía valorarse la recuperación de una orden concreta: la de llevar a efecto los capítulos referidos a la minoría musulmana acordados por la Congregación de la Capilla Real, convocada por Carlos I en 1526 y que, por distintas circunstancias contextuales salvo las que hacen referencia al pacto fiscal, no se habían aplicado.

Las Sinodales que en tal convocatoria se aprobaron y que muy probablemente el propio arzobispo trajera escritas, constan de setenta títulos y mil doscientos setenta y tres capítulos ${ }^{30}$; entre ellos destaca el clarificador apartado sobre los elementos propios de la doctrina cristiana, con especial incidencia en las oraciones a interiorizar/expresar en determinados momentos $^{31}$, así como en el ceremonial a seguir durante el traslado del viático a los enfermos ${ }^{32}$, procurando el mayor decoro posible. No obstante, el apartado más significativo, por sus ulteriores y significativas derivaciones prácticas, es el dedicado a la disposición del sacramento eucarístico en el interior de las parroquiales:

28. Este sacerdote riojano, fue prelado granadino entre 1546 y 1576. Formado en Alcalá, impartió Teología en Sigüenza y alcanzó las dignidades de canónigo magistral y doctoral en Cuenca. Siendo ya obispo de Granada, encabezaría la delegación española en Trento, participando activamente tanto en los debates como en las acotaciones de la actas. Cfr. A. Marín Ocete (1970).

29. L. del Mármol Carvajal (1797), 141-142.

30. Tal volumen da muestras del carácter reformista del prelado, impugnando algunos canónigos y beneficiados provinciales determinados artículos. Cfr. J. Tejado y Ramiro (1863), 361-388.

31. Son de especial interés las súplicas empleadas durante la consagración, cuando el celebrante alza la especie. Las mismas se convierten en práctica habitual para la archidiócesis, sirviendo de modelo para otras, como Toledo, recogiéndolo sus Sinodales de 1580. Cfr. J. GonzÁlez Torres (2016), p. 220

32. Las normas genéricas establecidas por Guerrero devienen de las directrices de Paulo V. De igual manera, serán seguidas al pie de la letra por las Constituciones sevillanas de los arzobispos Rodrigo de Castro (1585) y Fernando Niño de Guevara (1604), incluyendo algunos matices localistas. 
ha de situarse en un lugar decente en medio del altar mayor entre corporales de lino consagrados, y no entre papeles, y en una custodia de plata, metida en su relicario; el cual este adornado por de dentro con toda limpieza y decencia, con cortinas de seda, cerrando con su llave, la qual tendrá el cura y lo renovara en invierno, de quinze en quinze días, en verano de ocho a ocho días; y aya delante del, lámpara que arda de día de y de noche ${ }^{33}$.

Tales premisas ahondan en la importancia otorgada a las especies sacramentales. No ya solo dispuestas en un lugar concreto para su veneración dentro del espacio sacro sino, también, cuando sean objeto de cultos particulares, como ocurre en la festividad del Corpus Christi o en las ceremonias mensuales de las cofradías eucarísticas. Un clima devocional que tiene por objeto servir de catequesis visual para los 'cristianos nuevos', habida cuenta de su poco convencimiento en la transubstanciación así como en el aparato litúrgico-teatral con el que se envuelven tan significativas prácticas.

Informado el rey sobre lo dispuesto, este remite las apreciaciones granadinas al Consejo real, presidido por el Inquisidor general y obispo de Sigüenza, Diego de Espinosa. Examinadas las opiniones, teniendo en cuenta que hasta entonces toda actuación no había hecho más que ahondar en un sentimiento de venganza por parte morisca, deciden ratificar lo acordado en el sínodo conminando a su vez al monarca a reunir de nuevo al Consejo, en Madrid y presidido por él mismo, para que supervisara y amparara tales aspectos. A la misma asisten numerosas personalidades, resolviendo finalmente que si los moriscos recibían el bautismo y el nombre de cristianos, "lo habían de ser y parecer, dexasen el habito y la lengua, y las costumbres de que usaban como Moros" $" 34$. De esta manera quedaba recogido en la Real Cédula fechada el 4 de mayo de 1566, trasladada de inmediato tanto a la Audiencia de Granada como al arzobispado.

Para ello se establece un plazo de tres años en los cuales la minoría musulmana debería aprender la lengua castellana, prohibiéndose hablar, leer y escribir su idioma materno -tanto en público como en privado-. De igual manera, debían entregar los libros arábigos a la Audiencia real para que esta revisara su contenido, a la par que no usar prendas tradicionales como marlotas, almalafas o calzas, dejando las mujeres sus caras al descubierto. Otras costumbres también debían examinarse, sobre todo las referidas a las zambras y bailes llevados a cabo en las bodas, que debían adecuarse

33. P. Guerrero (1572), 98r.

34. Ibidem, 142-143.

(C) Baetica. Estudios Historia Moderna y Contemporánea, 38, 2018, 79-113. Facultad de Filosofia y Letras, Universidad de Málaga. Departamento de Historia Moderna y Contemporánea 
estrictamente a lo contenido en el ordo litúrgico. Cuestiones que, además de ser pregonadas públicamente, fueron trasladadas de manera directa a la comunidad morisca a través del canónigo Alonso de Horozco, regente de la colegiata de san Salvador, en el Albaicín, y conocedor de la lengua arábiga.

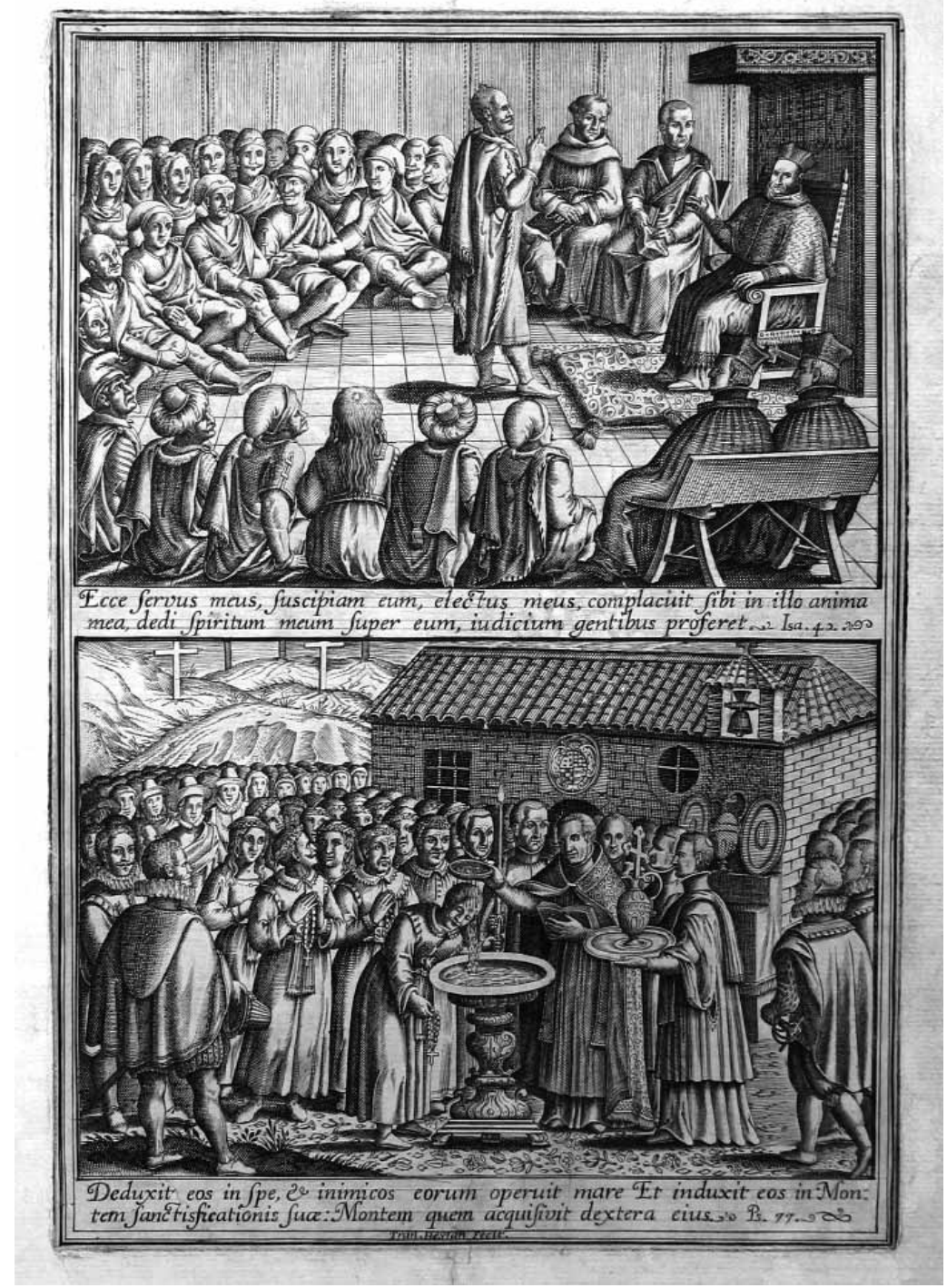

Imagen 3. Dibujo de Girolamo Lucente y grabado de Francisco Heylan (ca. 1612). El arzobispo Guerrero, reunido con los moriscos y celebrando bautizos en el Sacromonte. 
Los moriscos rechazaron taxativamente estas cuestiones. Pese a las continuas llamadas a la recapacitación así como a la defensa de su lengua, vestimentas y demás costumbres musicales -que incluyen el acompañamiento a las procesiones del Corpus - explicitadas en el Memorial de Núñez Muley, no serán escuchados. El malestar será uno de los desencadenantes de la 'rebelión de las Alpujarras' comenzada en la víspera de la Navidad de 1568 y activa a lo largo de casi tres cruentos años. Del enfrentamiento, destaca el carácter fanático de los primeros combates en el ámbito rural, donde a las torturas y muertes de religiosos ${ }^{35}$ se le añade la destrucción de iglesias y numerosas profanaciones ${ }^{36}$. Hechos que, junto a otros, conllevaron la expulsión y destierro de numerosos moriscos a otras tierras ${ }^{37}$.

Idéntico espíritu al demostrado por el arzobispo Guerrero es el que anima a las diócesis sufragáneas de Málaga (1572) y Almería (1607) a celebrar sus particulares sínodos bajo la autoridad de los prelados Francisco Blanco Salcedo y fray Juan de Portocarrero, respectivamente. En el caso malagueño, además de la unificación de ritos, se refuerza el convencimiento de la presencia real de Cristo en la Eucaristía y se incentiva la comunión frecuente entre los fieles ${ }^{38}$; aspectos cruciales desde el punto de vista pastoral y catequético con los que enfrentarse a la amenaza morisca que, en gran número, se oponen a cumplir con el credo cristiano en núcleos de la Axarquía. No en vano, las presiones ejercidas por parte del obispo sobre estos a partir de las visitas hechas por sus provisores y las instrucciones dadas ex profeso a los sacerdotes del lugar, derivan en la imposición de numerosas multas económicas ${ }^{39}$. La respuesta, a partir de abril de 1569 y reproduciendo las actuaciones que ocurren en las Alpujarras, no se hace esperar: grupos moriscos destrozan iglesias en VélezMálaga, Marbella y Ronda.

La problemática tiene visos de continuidad en Almería, donde el obispo Antonio Carrionero de Vabilafuente prioriza la actuación contra los

35. Entre sacerdotes y frailes, el cálculo asciende a 148 personas. $C f r$. J. CARo Baroja (1976), 177-178.

36. A. Domínguez Ortiz y B. Vicent (1993), 46. Es evidente que la comunidad musulmana, al rechazar el sacramento eucarístico y, por ende, la presencia de Cristo en él, sí reconocía la importancia que para la Iglesia representaba tal significación.

37. El proceso jurídico queda explicitado en Y. Quesada Morillas (2008), 1-27; de igual manera, el estudio del panorama nacional e internacional en el que transcurre tales disposiciones lo ofrece L. Martínez Peñas y A. Herreros Cepeda (2011), 2073-2082.

38. Cfr. con el segundo apartado de F. Blanco Salcedo (1573), s. f.

39. Una aproximación a estas cuestiones corresponde a J. Suberbiola Martínez (1995), 335-355. 
moriscos a través de varias normativas para aplicar, a través de ellas, los dictámenes del Sínodo granadino ${ }^{40}$. En este sentido, destaca la evolución de su propio pensamiento ya que, de demostrar cierta condescendencia hacia los 'cristianos nuevos', derivará hacia una oposición frontal a estos al observar que todos sus esfuerzos resultan infructuosos ${ }^{41}$. Así pues, no será hasta la llegada a la prelatura almeriense de Portocarrero cuando se celebre el sínodo que, por supuesto, denota un claro espíritu eucarístico.

En todo caso, siempre prevale el signo adoctrinador en tales directrices, en paralelo a las cuestiones políticas o sociales fomentadas por el poder civil. Así se refleja en las Sinodales de Sevilla, de 1572 que, inspiradas en las normas accitana y granadina, hace mención expresa a la realidad multiétnica de la diócesis sevillana, "porque por el levantamiento de los moriscos del Reyno de Granada se han repartido por el Reyno y mucha parte de ellas viven en este Arzobispado", de tal manera que "Nos conviene como prelado suyo dar orden como sean todos doctrinados y enseñados y se confiesen y oygan missa y se tenga particular cuenta de ellos" ${ }^{\prime 4}$.

Es por ello que, en paralelo a las doctrinas sinodales, se lleve a cabo una 'popularización' de las mismas en pro de su conveniente asunción y desarrollo ${ }^{43}$. En este sentido, resulta significativa la abundancia de catecismos publicados ad hoc. Esta literatura doctrinal está destinada a clérigos para que estos sean capaces de enseñar los principios fundamentales de la religión cristiana a los moriscos. Este interesante conjunto documental se divide en dos categorías básicas: de un lado, los textos que refutan errores $\mathrm{y}$ falsas creencias de la religión islámica $\mathrm{y}$, por otro, los que denotan un

40. No obstante, convencido de la significación sacramental y del poder que -según el credo cristiano- de esta deriva, acometerá una serie de reformas litúrgicas en la catedral. Véase el apartado dedicado a ello.

41. Destaca al respecto un memorial enviado al rey en el que solicita la prohibición real al uso de ropajes de corte musulmán, el abandono del idioma árabe, el impedimento a movimientos migratorios, la negativa a poseer esclavos negros, la supresión de los ritos purificadores islámicos o la obligación a todo noble morisco de enviar a estudiar a sus hijos a Castilla. La confrontación es tal que la muerte sorprende al prelado en pleno desarrollo de la contienda. Cfr. J. J. López Martín (2004), 152-153.

42. C. Rojas y Sandoval (1572), s. f.

43. Los ideales de cambio advertidos desde Roma desde mediados del XVI tienen una amplia proyección en la propagación de escritos y la edición de trabajos pedagógicos que sirven de soporte teórico a tal espíritu. En Andalucía y, concretamente, en la diócesis de Jaén, destaca el publicado por el clérigo Gutierre González, cuyo radio de acción sobrepasa las propias fronteras regionales para convertirse en modelo a seguir, incluso, en las Indias occidentales. Vide M. ${ }^{a}$ A. López Arandia (2007). 
carácter pragmático en la explicitación de las bondades de la fe $\mathrm{fe}^{44}$. Es más, el inicio de tales prácticas docentes tiene su origen en un autor esencial: el primer arzobispo de Granada, el fraile jerónimo Hernando de Talavera. Su labor pastoral al frente de la recientemente creada diócesis (1493-1507) le lleva a realizar una estratégica labor de captación de la población musulmana de manera pacífica ${ }^{45}$. A su mano corresponde la Breve doctrina y enseñanza que ha de saber y de poner en obra todo christiano y christiana. En la cual deben ser enseñados los moçuelos primero que en otra cosa (Granada, 1499), obra a la que se suman directorios, traducciones y textos hagiográficos ${ }^{46}$.

Toda esta documentación supone el intento de convencer a los moriscos de la necesidad de apartarse de sus antiguas creencias y abrazar la fe cristiana, siendo conscientes sus autores que la problemática de las conversiones forzosas requerían de un proceso de conocimiento catequético. En este sentido, el acercamiento al rito debiera comenzar por establecer las pautas de comportamiento cuando se accede a una edificación sacra. Funciones esenciales que quedan patentes en la breve Instrucción dada por Talavera hacia 1500 a los vecinos moriscos del Albaicín:

Lo primero que olvidéis toda cerimonia y toda cosa morisca en oraciones, en ayunos, en pascuas y en fiestas, y en nacimientos de criaturas y en bodas, y en baños, en mortuorios y en todas las otras cosas. [...] Que todos sepáis [...] signar y santiguar, entrar y estar en la iglesia y tomar agua bendita, decir Pater noster y Ave María y credo, y adorar a allí a nuestro Señor en la Santa Misa ${ }^{47}$.

El último aspecto es clave: la veneración de Cristo-eucaristía. De ahí que los esfuerzos se centren en explicitar el sentido de la comunión así como

44. De entre el extenso catálogo, destacan, en títulos abreviados: Vocabulista aravigo, de fray Pedro de Alcalá (1505); Libro llamado Anti-Alcorano, de Bernardo Pérez de Chinchón (1532); Confutación del Alcorán y Secta, de Lope de Obregón (1555); o Catecheses Mystagogicae, de Pedro Guerra de Lorca (1586). Un estudio pormenorizado de estos lo ofrece A. Hernández SÁnchez (1955) y otro, más genérico, M. ${ }^{a}$ J. FramiñÁn de Miguel (2005), 25-37.

45. Pudo influir en ello su condición de descendiente de judíos. Convencido de la necesidad de establecer un relaciones de amistad, hizo además de intermediario en conflictos políticos de la comunidad islámica granadina y defendió el conocimiento de la lengua árabe entre célibes. Cfr. M. Bataillon (1986), 58.

46. El talante catequético de sus obras es estudiado, entre otros, por J. Montoya Martínez (2007), 47-65

47. H. De Talavera (ca. 1500), s/f. Texto recogido al completo en T. Azcona (1964), 761 763. 
en la actitud con que esta debe recibirse. Al respecto, fray Pedro de Alcalá establece un curioso parangón entre la limpieza corporal que los propios musulmanes ejercían cuando se predisponían a rezar en las mezquitas con la espiritual que requiere la conciencia cristiana para confesión de los pecados, exhortando sobre los beneficios particulares que reporta la manducación de la hostia consagrada: "Este pan celestial que da vida a todos aquellos que dignamẽte lo reciben" 48 . El propio fraile reconoce las dificultades de su comprensión, argumentando que dicho proceso "está en alto secreto" y que por lo tanto se debe "creer verdaderamente de corazón y anima".

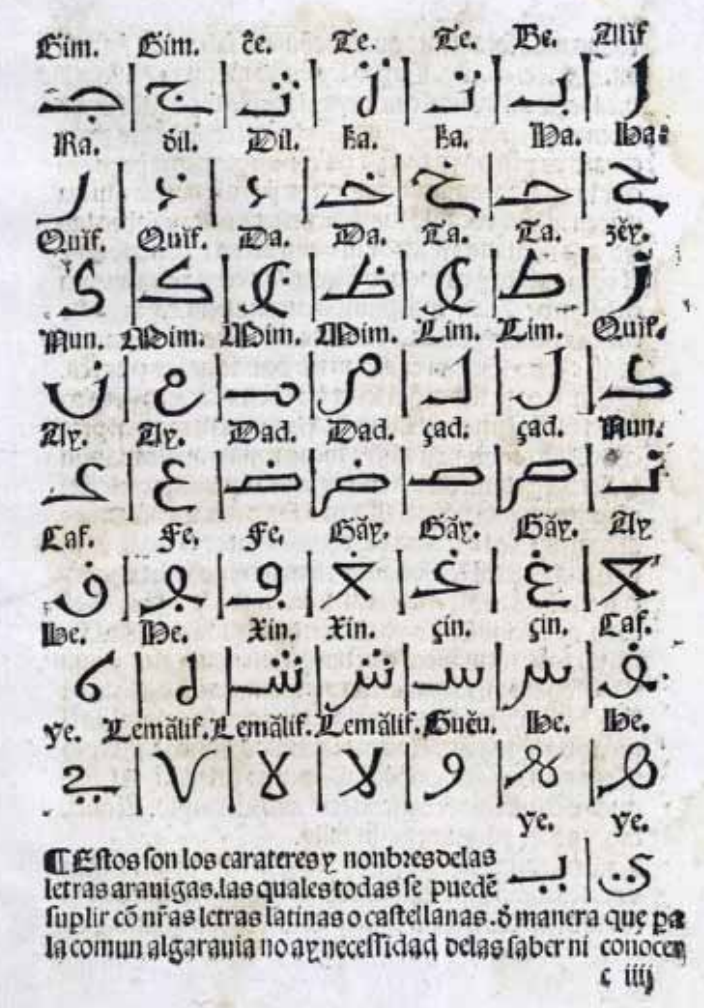

Imagen 4. Pedro de Alcalá (1505). Página del Arte para ligeramẽte saber la lẽgua araviga en la que traduce los caracteres fonéticos de dicho idioma al castellano.

48 P. dE AlCalÁ (1505), s/f. Las siguientes citas se corresponden a fragmentos que siguen a la primera. 
En esta última cuestión ahonda el Cathechismo redactado por un anónimo jesuita en Granada hacia $1588^{49}$ : "las cosas divinas exceden infinitamente a todo entendimiento criado, no solo al humano sino al angélico y que el testimonio de nuestra fe es 'Dios lo dize', que no puede engañar ni ser engañado" 50 . De tal forma que justifica tan compleja conceptualización aludiendo a que se trata de uno de los misterios de la redención con la que la divinidad expía los pecados de los seres humanos. Y si el origen de estos devienen de la ingesta de la manzana en el Jardín del Paraíso, "quiso el Señor que tengamos otro arbol de cruz, fruto de la virgen que lo pario" ${ }^{51} \mathrm{y}$ del que proceden las especies eucarísticas. Matiza el autor que "el Hijo de Dios encarnado [...] se quedo en el santissimo sacramento, del qual vienen a cada uno que bien lo recibe los infinitos thesoros de su santa venida en carne al mundo" 52 . Y si, en efecto, hubiese mayores dudas sobre cómo un trozo de pan puede significar la presencia misma de Cristo, se subraye que "la omnipotencia divina que haze esso haze también que el santissimo cuerpo del Señor este en la ostia no solo virtualmente ni accidentariamente sino real y substancialmente" 53 .

No obstante, el magisterio más preclaro es el que ofrece Martín Pérez de Ayala. Su Catechismo para instrvccion de los nvevamente convertidos de moros $(1599)^{54}$ comienza sentenciando que "Dios es inexplicable, porque es incomprehensible por su infinidad" 55 , de ahí que cualquier explicación de su mensaje se haga por medio de un lenguaje limitado. Rebatiendo los más significativos preceptos del Islam, el prelado argumenta su opinión sobre la necesidad de conversión al cristianismo, cuya prevalencia sobre otras creencias se sustenta al constituir "un verdadero conocimiento y noticia de Dios, y de sus propiedades y efectos, y de cómo ha de ser servido, adorado y reverenciado" ${ }^{56}$. De ahí que sea la fe el método que posibilite la comprensión de los grandes misterios de este credo y la necesidad de

49. Manuscrito de 570 folios, conservado en la Biblioteca de la Abadía del Sacromonte, Granada. Está escrito a modo de diálogo entre un sacerdote y un "christiano nuevo de morisco". Consultada la edición de L. Resines (2002), 161-322.

50. Ibidem, $75 \mathrm{v}$ (original), 237 (edición).

51. Ibidem, $76 \mathrm{v}-238$.

52. Ibidem, 77r-238.

53. Ibidem, $77 \mathrm{r}-77 \mathrm{v}-239$.

54. La historiografía entiende que el texto original es anterior a la fecha de impresión, ordenada por el prelado valenciano Juan de Ribera.

55. M. Pérez de Ayala (1599), 15-16.

56. Ibidem, 35-36. 
aplicarlo a la vida diaria a imitación del "nuevo hombre, Christo nuestro Redemptor, que es todo fundamento de la verdadera religión" ${ }^{57}$.

Tal convencimiento le lleva a exponer que la existencia de otras creencias son fruto de la acción del demonio, puesto que tal situación es siempre fuente de divisiones y enfrentamientos. De ahí que la misión del fiel sea la de luchar contra aquellas tentativas dogmáticas que pongan en duda los principios cristianos, debiendo estar precavido ante posibles ataques. Ante ellos, deberá utilizar sus propias armas, que "son todas espirituales: [...] la sancta palabra y doctrina de Dios, la fe, la confiança, y esperanza en Dios y en sus promesas, la charidad, la oración, el exercicio de los sacramentos, y mortificación de la Cruz" "58; todas ellas ejercen además un papel taumatúrgico: actúan como "medicinas del alma"

Siguiendo tal hilo argumental, las referencias que el autor hace sobre la Eucaristía son extensas, partiendo del hecho clave que en la misma subyace. El ejercicio didáctico realizado para enfatizar y aclarar la presencia permanente de la divinidad se centra, en primer lugar, en el seguimiento del ordo litúrgico por el propio celebrante, quien:

por la fuerça del infinito poder de Dios (a quien nada le es impossible) mediante aquellas palabras que [...] dize en la Missa, quando consagra, que son las que dixo el mesmo Christo, dexa de ser la substancia del pan y del vino, y se haze presente real y verdadera, y sacramentalmente debaxo de los accidentes del pan y del vino todo Christo, en todo, y cada parte del Sacramento, por un modo inefable, a solo el posible ${ }^{60}$.

Posteriormente, partiendo de la cita joánica, refuerza tal sentido al reinterpretar la promesa salvífica de Jesús de darse a sus seguidores como alimento y bebida espiritual. De tal forma que ambas dimensiones queden unidas en una sola realidad de modo que "el cuerpo vivo no está sin alma, ni la sangre sin cuerpo; ni cuerpo y alma de Christo sin divinidad: hase de creer que está allí todo Christo, verdadero Dios y hombre" ${ }^{61}$. En ello radica el sentido mismo del sacrificio del altar, cual rememoración continua del juramento mesiánico recogido en el Evangelio y que, además, recuerda constantemente la expiación de los pecados a partir de la

57. Ibidem, 53.

58. Ibidem, 227.

59. Ibidem, 371-372.

60. Ibidem, 377 .

61. Ibidem, 378.

(C) Baetica. Estudios Historia Moderna y Contemporánea, 38, 2018, 79-113.

Facultad de Filosofia y Letras, Universidad de Málaga. Departamento de Historia Moderna y Contemporánea 
muerte redentora de Jesús: “yo estaré con vosotros todos los días, hasta el fin del mundo" ${ }^{\prime 2}$.

De ahí que su recepción -a través de la comunión ${ }^{63}$ - comporte una actitud concreta por parte del fiel. Este debe ser consciente que se encuentra ante un "manjar celestial y divino"64, distinto de los que come a diario y necesario para el mantenimiento de su alma. Previamente, debe adoptar una postura de renuncia al pecado y una actitud de reconciliación con el resto de los hermanos que, de no cumplir, puede provocar efectos negativos, pues participar de la comunión en circunstancias no debidas "suele tornar en ponçoña para el cuerpo" ${ }^{65}$. En todo caso, los beneficios de comulgar son extensos: disminuye el deseo de pecar, ayuda a alcanzar la perfección cristiana, conforta el alma contra las tentaciones y permite mantener la esperanza en la vida eterna; aspiraciones que están presentes en los primeros seguidores de Cristo, los santos y los mártires, quienes participaron del banquete eucarístico entendiendo que se trata de un "propio manjar de hijos" $" 66$ y que, además, "representa el misterio y beneficio de la Passion de nuestro Redemptor Iesu Christo"67.

\subsection{El experimentalismo sacramental en las catedrales del reino de Granada}

Evidentemente, todo este trasfondo teórico requiere de otras dimensiones que lo hagan más entendible por los fieles, poco habituados a disquisiciones intelectuales. En este sentido, las capillas mayores de las catedrales de Granada, Málaga, Almería y Guadix van a convertirse, desde mediados del siglo XVI, en escenario donde se proyecte plástica y simbólicamente

62. Mateo 28, 20. El argumentario en torno a dicha cita es uno de los más recurrentes ejemplos de la parenética del siglo XVI. Véase al respecto el discurso LXXVIII, titulado Caro mea vere est cibus, recogido por A. DE VILlegas (1589), 291-294r.

63. La frecuencia con la que, según el prelado, debe realizarse esta es, al menos, una vez al año, coincidiendo con la festividad de Pascua de Resurrección. No obstante y en virtud de la vida de cada morisco, se podrá realizar cuantas sean necesarias, siempre contando con la aquiescencia del confesor. De igual manera se permite la manducación sacramental cuando exista en peligro de muerte, se emprenda algún viaje largo o se esté en preparación para la guerra.

64. M. Pérez de Ayala (1599), 379.

65. Ibidem, 380 .

66. Ibidem, 382 .

67. Ibidem, 400 .

(C) Baetica. Estudios Historia Moderna y Contemporánea, 38, 2018, 79-113. Facultad de Filosofia y Letras, Universidad de Málaga. Departamento de Historia Moderna y Contemporánea 
el culto eucarístico ${ }^{68}$. Tales actuaciones responden, en un primer momento, al renovado clima de espiritualidad sacramental que se implementa en el orbe católico a partir de la recepción de las actas de Trento y del desarrollo de los concilios; no obstante, en el caso que concierne a los antiguos territorios nazaríes, la apuesta refuerza aún más la encendida problemática contra la comunidad morisca.

En este sentido, las obras de terminación de la cabecera de la catedral granadina viven una extensa historia constructiva; no en vano y pese a las modificaciones realizadas sobre el planteamiento original, la intención de concretar un conjunto edilicio denotativo del poder cristiano sobre el derrotado mundo islámico nunca se desecharía ${ }^{69}$. La contratación en 1528 de Diego de Siloé, de quien parte una solución del espacio presbiterial 'a lo romano', va a significar la plasmación visual de la nueva Iglesia. La disposición central de un tabernáculo eucarístico diseñado por el arquitecto burgalés en $1561^{70}$ aglutina, de un lado, las referencias teológicas puestas en valor tanto en el concilio de Trento como el provincial granadino que promoverá el arzobispo Guerrero y, de otro, las connotaciones estructurales inmanentes a dicha estructura, relacionables enteramente con el gran referente impulsado en el Duomo de Milán por el cardenal Borromeo y, por supuesto, con el dispuesto en el centro del retablo del monasterio de san Lorenzo de El Escorial.

El 17 de agosto de 1561 se celebra un solemne pontifical y se traslada con sumo boato el santísimo sacramento hasta el tabernáculo, elaborado con maderas nobles en apenas un mes. Su disposición centralizada no solo obedece a aquella antigua tradición cristiana que otorgaba a tal estructura funciones focalizadoras de la atención del fiel sino que, a su vez, incorpora una significación simbólica al convertirse en puntal arquitectónico a partir del cual se elabora un programa iconográfico ad hoc en las superficies murarias que cierran el espacio presbiterial. En este sentido, el edículo granadino forma parte de un mensaje mesiánico en donde la promesa de Cristo de no abandonar a quien le sigue se patentiza a través de la presencia, como en Pentecostés, de su madre, María, y de sus primeros discípulos ${ }^{71}$.

68. Estas transformaciones, a su vez, actúan cual modelo para el resto de parroquias diocesanas, incluso para centros monásticos, actores activos de una fiebre eucarística coral que tendrá en los siguientes dos siglos, momentos de un extraordinario auge artístico. Vide J. González Torres (2016), 408 y ss.

69. Vide E. E. Rosenthal (1990).

70. Documentado por F. Bermúdez de Pedraza (1652).

71. Cfr. J. González Torres (2003) p. 318. 
De esta manera, el triunfo de la fe cristiana quedaba patentizado sobre la aniquilación de la herejía como necesidad para expiar -según su propio pensamiento- los ochos siglos de ocupación musulmana de la ciudad a partir del 'arma' pastoral más contundente: la presencia transustanciada del Nazareno inserta en un tempietto exento que permitía, cuando así lo requería la rúbrica litúrgica, su veneración sacramental.

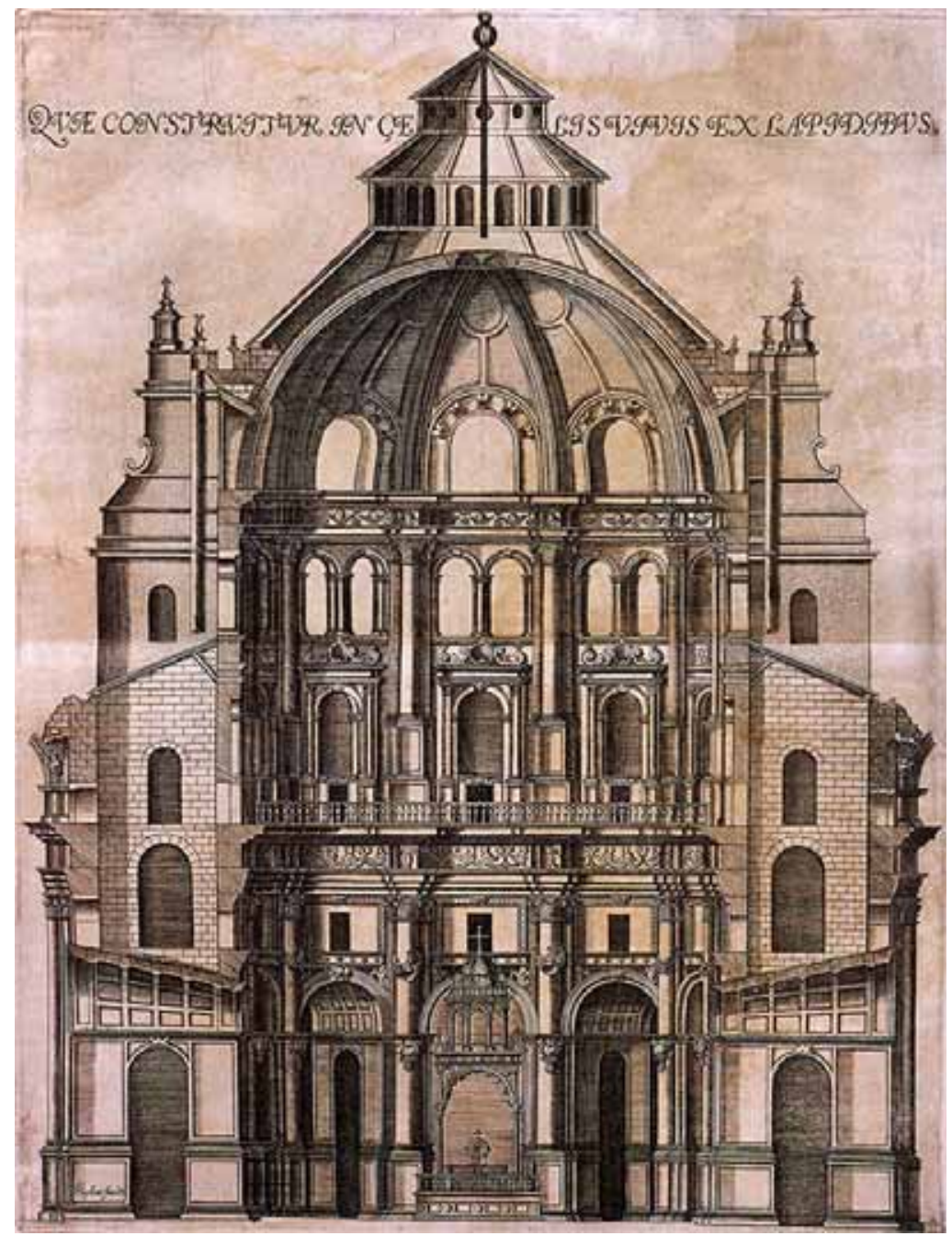

Imagen 5. Dibujo de Girolamo Lucente y grabado de Francisco Heylan (ca. 1612). Corte axial de la cabecera de la catedral de Granada en donde se observa, en primer término, el tabernáculo de Siloe. 
Esta novedosa disposición no pasaba desaperciba para los fieles y visitantes: "en medio desta capilla se levanta [...] un tabernáculo dorado, con quatro colunas corintias, y sobre ella quatro arcos; [...] debaxo [...] está el Alta Mayor, con tanto artificio puesto, que en cualquier capilla que se ponga de la Iglesia se descubre, y se veen celebrar en el los oficios divinos"72.

En Málaga, la materialización del programa eucarístico en la capilla mayor catedralicia es una de las empresas más complejas que marcan las décadas finales del siglo XVI. La lentitud con la que se venían desarrollando los trabajos constructivos del recinto, con cambios en la dirección de las obras y modificación de elementos estructurales no son obstáculo para que, hacia 1575, se concierten las primeras labores escultóricas bajo la supervisión de Diego de Vergara ${ }^{73}$; el espacio sobre el que estas se dispondrían destaca por la diafanidad de su estructura que, además de señalizar la superficie altopresbiterial, actúa a modo de biombo traslúcido entre esta y la girola que rodea exteriormente su perímetro. Singularidad que se completa a través de cinco arcos que, a un doble nivel, se abren entre grandes intercolumnios.

Entre 1579 y 1589, el pintor italiano Cesare Arbassia será contratado por el prelado Francisco Pacheco con la intención de proceder, en un primer momento, al dorado de estructuras y paños ornamentales para pasar, en los últimos dos años, a la realización de cinco frescos sobre episodios de la Pasión de Cristo y diecisiete tablas para un tabernáculo central. Con respecto a las dos últimas tareas, resulta esencial la llegada a la diócesis de un nuevo obispo: el noble cordobés García de Haro y Sotomayor Portocarrero. Este impuso como fecha final para la consagración del espacio el 31 de agosto de 1588, a pesar que las obras continuasen en las décadas siguientes.

Es bastante probable que, en función de otras iniciativas impulsadas por el eclesiástico, este ostentara la dirección teológica del definitivo programa iconográfico que, partiendo de las esculturas primitivas, se centrara en el edículo sacramental y su conexión con las escenas pasionistas; de hecho, la estructura centralizada tendría un diseño turriforme, escalonado, incorporando en sus distintos niveles escenas pintadas de inspiración veterotestamentaria a las que se dotaría de ciertas connotaciones emblemáticas,

72. F. Bermúdez de Pedraza (1608), 80r y 81a. Años después, y ante el deterioro de los materiales primigenios, el edículo sería sustituido por otros, sin menoscabo de su significación cristológica.

73. R. Camacho Martínez (1999), p. 15-34. 
capaces de establecer una asociación visual entre la imagen de conjunto y las filacterias escritas con mensajes mesiánicos. Estas acabarían por otorgarle su sentido más prístino ${ }^{74}$.

La trascendencia litúrgica e iconológica de esta actuación es notable para la historia constructiva de la Iglesia española, en un tiempo donde las ideas del renovado credo están aún en fase embrionaria. Los recursos estéticos serán capaces de crear un efecto global resplandeciente, enmarcado por la estructura de la fábrica catedralicia, en línea con otras soluciones escenográficas desarrolladas por el pintor de Saluzzo en trabajos españoles e italianos. El resumen simbólico resultante es el de una capilla vertical, conceptualmente configurada a semejanza de un palacio místico en el que el principal morador habita de manera fehaciente en el ciborio sacramental. Este rememora de forma continuada el sacrificio de Cristo y su exaltación como sacerdote, víctima propiciatoria y rey, incardinando su acción redentora a partir de las prefiguras del Antiguo Testamento y su proyección sobre las escenas que plasman su cruenta pasión.

La teofanía eucarística que marca el tabernáculo irradia en múltiples direcciones, actuando cual remedo de la acción divina; de un lado, haciendo partícipes a los fieles -la Iglesia sufriente- que se dispondrían en el espacio congregacional; y, de igual manera, a los miembros de los estratos triunfante y militante, representados por las antiguas estatuas martiriales, los ancestros que prefiguran la presencia mesiánica y la de los profetas que anuncian el tormento de cruz, junto a los Padres de la Iglesia, intérpretes de la nueva alianza. La bóveda que cubre la capilla incorpora a su vez la representación del misterio de la encarnación en el que María de Nazaret recibe la visita del arcángel Gabriel, junto a relieves alegóricos de la Fe y la Caridad; con tales presupuestos, la alusión a la esperanza en que la venida de Cristo haga cumplir lo profetizado, se cierra definitivamente.

Esta lectura no solo traduciría visualmente el triunfo sacramental propuesto por Trento, sino que, a su vez, redundaría en claro mensaje en alusión a aquellos que renuncien a la fe o adopten creencias contrarias a esta. La unidad eclesial en torno a la figura de Cristo a partir de la legitimidad del credo católico, mostraría el camino de su martirio cual modelo a seguir por sus prosélitos seguidores a la vez que sólido argumento propagandístico capaz de convencer al más incrédulo.

En Almería, el experimentalismo espacial de signo cristológico-funerario ya había sido tratado a partir de las obras patrocinadas por el obispo fray 
Diego Fernández de Villalán y su deseo de recibir sepultura en la capilla del ábside, uno de los espacios más antiguos del recinto. Sin embargo, será bajo la prelatura de Antonio Carrionero, ya citado anteriormente, cuando se consagre la catedral; momento que discurre en paralelo a la labor pastoral desempeñada por este en pro de la conversión efectiva de los musulmanes. $\mathrm{Al}$ respecto y teniendo como referencia las soluciones dadas a la cabecera granadina, el prelado impulsa la construcción de un tabernáculo para la capilla mayor, con probable diseño del maestro mayor de obras, Juan de Orea. Su disposición centralizada ${ }^{75}$ y la colocación de dos púlpitos bajo el arco toral, denotan la intencionalidad de estas acciones: la significación eucarística unida a la predicación, entendiendo esta última como medio vehicular a través del cual adoctrinar los conceptos más complejos del credo cristiano.

No podía ser menos la catedral de Guadix, sobre todo teniendo en cuenta las aportaciones catequéticas de Martín Pérez de Ayala. Sin embargo, la dilatada construcción de la fábrica, la multiplicidad de artífices, maestro de obras y canteros, la falta de medios económicos, la fugaz permanencia de otros obispos, los reverses políticos y, sobre todo, la falta de un planteamiento constructivo de conjunto, impiden la terminación ornamental del recinto -que incorpora lenguajes distintos-, hasta bien entrado el siglo $\mathrm{XVIII}^{76}$. A pesar de ello, parece evidente que la capilla mayor, desde la segunda mitad del XVI, quedara dedicada al culto y la veneración eucarística; idea que queda reforzada a partir del impulso dado a la procesión del Corpus Christi.

\subsection{El impulso al culto eucarístico en el terreno más popular: cofradías y capillas sacramentales}

El asociacionismo en torno a las cofradías eucarísticas y el inicio de la construcción de las capillas sacramentales en parroquias y conventos constituyen, a lo largo del siglo XVI, una dimensión mucho más cercana al pueblo. En paralelo a este desarrollo deben entenderse las procesiones

75. Al respecto de su imagen final no se tiene constancia documental al haber sido sustituido en el siglo XVIII por otra estructura distinta, aunque de igual significado.

76. Cfr. J. M. Gómez-Moreno Calera (1987), 107-117. El tabernáculo central que hoy se conserva es diseño del arquitecto gallego Domingo Lois de Monteagudo. La estructura se incardina iconológicamente con un ciclo de pinturas marianas, fechadas hacia 1764 y situadas en el primer nivel del presbiterio. 
del Corpus Christi, un cortejo 'parlante' en el que se ponen en escena las creencias sacramentales y que culminan en la custodia procesional en la que se exhibe la hostia consagrada. En definitiva, tal esfuerzo procesionista queda conectado al interés por adoctrinar a los diversos grupos sociales de una localidad, traspasando el ámbito privado del recinto religioso e incardinándose en la trama urbana pública ${ }^{77}$. De ahí el amplio desarrollo de un catálogo iconográfico adherido a arquitecturas efímeras que prolifera en la centuria y que alcanza altas cotas de espectacularidad escenográficoteatral en el Barroco.

Esta ostensible religiosidad es fruto de una mezcla singular entre lo oficial y lo privado, lo popular y lo culto. De ahí que a estas prácticas devotas estén llamados a participar todos los estamentos sociales; en su esencia, son un elemento básico para el estudio de cómo la norma trentina se difunde y hace prevalecer el comportamiento piadoso como remedio para erradicar costumbres poco decorosas. La conjugación entre la normativa eclesiástica, de un lado, y la particular idiosincrasia de los habitantes de una localidad, de otro, otorgan a este tipo de iniciativas un carácter clerical tachonado de connotaciones más propias de la religiosidad local, las cuales aportan, en cada tiempo y lugar, características singulares.

El asociacionismo -y en especial, el que tiene por objeto la veneración eucarística- se incardina bajo la concepción jerárquica de la Iglesia post-conciliar ${ }^{78}$. A esta proliferación también contribuyen franciscanos, dominicos, mercedarios o carmelitas, entre otras órdenes, favorecidos por los repartimientos realizados en las diócesis de Málaga, Almería y Granada como consecuencia de las anexiones territoriales a la Corona castellana. Cada uno de estos Institutos promoverá la construcción de sus respectivos cenobios casi siempre fuera de las murallas nazaríes perimetrales de cada urbe. Como con estas promociones se cumplía el precepto trentino de incentivar la participación de los laicos, es complicado no encontrar una población andaluza a finales del siglo XVI -tanto en la zona occidental como oriental- que no dispusiera de una confraternidad eucarística.

La consecución de los fines que originan las cofradías sacramentales comporta, a su vez, una forma pía de expiación de los pecados y la posibilidad de alcanzar, tras la muerte, la vida eterna. No obstante, se trata de prácticas interiorizadas, no formalistas, capaces de promover la participación

77. Vide A. García Pedraza (2002), 172 y ss.

78. Las diferencias con las primitivas asociaciones medievales, en especial las pasionistas, son más que evidentes. Véanse algunos ejemplos en W. A. Christian (1991). 
de los fieles en los cultos y de cumplir, por su parte, con el renovado ritual litúrgico, de ahí la enorme popularidad que algunas de estas instituciones alcanzan. Incluso en las localidades más pequeñas, estas organizaciones son las únicas con potencial suficiente para afinar la fe del pueblo y promover, a su vez en ellos, un sentimiento de identidad. De ahí que las familias nobles se conviertan en patronas de las mismas, haciéndose cargo de donaciones y pagos de piezas para el patrimonio artístico y, con el paso del tiempo, sufragando la remodelación de los altares donde estas corporaciones tienen su residencia canónica para albergar capillas sacramentales dotadas de un aparato discursivo puesto al servicio del dogma, el culto y la religiosidad.

Y, en paralelo, la festividad del cuerpo y de la sangre de Cristo, adquiere en el antiguo reino granadino un carácter altamente militante. No se trata solo de dignificar y expandir la devoción sino de hacer ver que, con su veneración, se conmemora de continuo el triunfo de la fe que hizo posible, en años anteriores, la derrota de las tropas nazaríes.

En Granada, incluso, la donación de un ostensorio para que sea procesionada la hostia en tal festividad por parte de Isabel, la reina católica, no es un hecho baladí. El ingreso de impuestos por parte del Concejo local para ese día y la constitución, en 1517, de la denominada 'cofradía del Corpus'79, son algunas de esas consecuencias directas. De igual manera, la creación de los conventos de Huécija -regentado por agustinos- y de las Alpujarras -monjas franciscanas-, auspiciados por la dama cortesana Teresa Enríquez, se convierten en centros desde los que emana la piedad eucarística hacia localidades cercanas, en cuyas parroquias se fundan cofradías sacramentales.

Por su parte, en Guadix y Baza, la festividad eucarística se implanta en 1518, colaborando en su mantenimiento las autoridades civiles a partir del establecimiento de juegos, entremeses y otras motivaciones lúdicas que llamen la atención de los moriscos, con tal de que estos participen en los cultos. Para ello cuentan incluso con dotaciones económicas enviadas por el cercano obispado de Almería que, a mediados de siglo, apuesta por tal decisión con tal de tener controlados a los 'nuevos cristianos' ${ }^{80}$.

79. Además de incentivar la devoción sacramental, esta asociación tiene a su cargo un hospital. Cfr. M. L. López-Guadalupe Muñoz (1996-1997), 303.

80. A. Gallego Burín y A. Gámir Sandoval (1968), 83. 


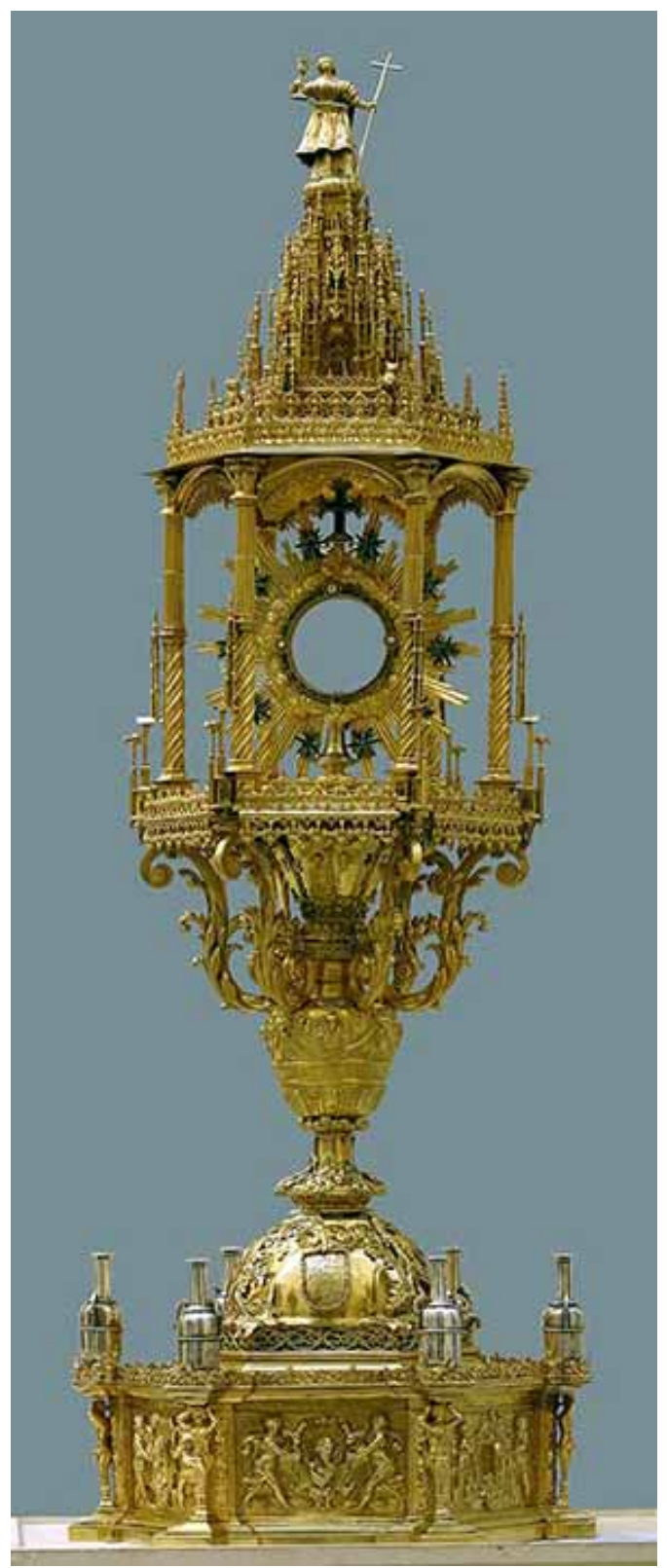

Imagen 5. Custodia de la catedral de Granada.

El cuerpo superior, de traza gótica y en donde se inscribe el viril, forma parte de la donación de la reina católica en 1501. El basamento octogonal corresponde al platero Francisco Téllez, quien lo elabora en varias fases entre 1531 y 1569.

(C) Baetica. Estudios Historia Moderna y Contemporánea, 38, 2018, 79-113. Facultad de Filosofia y Letras, Universidad de Málaga. Departamento de Historia Moderna y Contemporánea 
Un hecho cuanto menos paradigmático tiene lugar en Béznar, localidad al sureste del valle de Lecrín. En 1566 se funda una cofradía militar que tiene por objeto rescatar el viático robado a un beneficiado por parte de unos moriscos; el hecho, envuelto en legendaria tradición, culmina en la sierra de Tablate con la aparición de la hostia consagrada y el grito de “¡Mosqueteros, ahí está nuestro Dios!”, protagonizado por el capitán de la milicia ${ }^{81}$. El hecho se transformaría en los años siguientes en ritual festivo en el que los oriundos del lugar rememoran lo acontecido, exponiendo el sacramento en la capilla mayor de la parroquia y, posteriormente, teatralizando la escena referida a la caída de la noche.

\section{A MODO CONCLUSIVO}

Pese a tan notables esfuerzos por parte de los distintos estamentos eclesiásticos, el poder civil acabó por decretar la expulsión definitiva de los moriscos entre 1609 y 1610. Atrás quedaba una serie de actuaciones bien intencionadas que no cumplieron con los objetivos previstos. Los continuos altercados, con sus consiguientes desagravios, terminaron por abrir una vía que, en 1492, estaba completamente cerrada. Del respeto entre comunidades se pasaría, andando el tiempo, a la cerrazón más acérrima, desterrando de los territorios peninsulares a una población con la que, teórica y supuestamente, no se compartía ni la sangre, ni las creencias ni la cultura.

\section{BIBLIOGRAFÍA}

Alcalá, Pedro de (1505), Arte para ligeramẽte saber la lẽgua araviga, Juan Varela de Salamanca, Granada.

Atienza, Bartolomé y Angulo, Andrés de (1569), Recopilacion de las leyes destos reynos hecha por mandato dela magestad catholica del Rey don Philippe Segundo... t. II, Imprenta de Andrés de Angulo, Alcalá de Henares.

Bataillon, Marcel (1966), Erasmo y España, Fondo de Cultura Económica, México-Madrid-Buenos Aires.

Benítez Sánchez-Blanco, Rafael y Císcar Pallarés, Eugenio (1979), "La Iglesia ante la conversión y expulsión de los moriscos", en R. GARCíAVilloslada (dir.), Historia de la Iglesia en España, vol. 4, BAC, Madrid, pp. 255-310.

Bermúdez de Pedraza, Francisco (1608), Antigüedad y excelencia de Granada... Luís Sánchez, Granada.

81. A. M. Río (2006).

(C) Baetica. Estudios Historia Moderna y Contemporánea, 38, 2018, 79-113.

Facultad de Filosofia y Letras, Universidad de Málaga. Departamento de Historia Moderna y Contemporánea 
- (1652), Historia eclesiástica. Principios y progresos de la Ciudad y Religión Católica de Granada..., Francisco Sánchez, Granada.

Bleda, Jaime (1618), Corónica de los moros de España, dividida en ocho libros..., Felipe Mey, Valencia.

Camacho Martínez, Rosario (1999), "De mezquita a templo cristiano: etapas en la transformación y construcción de la Catedral de Málaga", en AA.VV., Retrato de la Gloria. Restauración del Altar Mayor de la Catedral de Málaga, Winterthur, Barcelona, pp. 15-34.

Caro Baroja, Julio (1976), Los moriscos del Reino de Granada. Ensayo de historia social, Istmo, Madrid.

Castillo Fernández, Javier (2013), La historiografía española del siglo XVI: Luis del Mármol Carvajal y su Historia del rebelión y castigo de los moriscos del Reino de Granada. Análisis históricos y estudio crítico, Universidad, Granada.

Christian, William A., JR. (1991), La religiosidad local en la España de Felipe II, Nerea, Madrid.

Domínguez Ortiz, Antonio y Vincent, Bernard (1993), Historia de los moriscos, vida y tragedia de una minoría, Alianza Universidad, Madrid.

El Alaoui, Youssef (1997-1998), "Ignacio de las Casas, jesuita y morisco", Sharq al-Andalus. Estudios mudéjares y moriscos, 14-15, pp. 317-339.

Fernández Collado, Ángel (2007), Historia de la Iglesia en España. Edad Moderna, Instituto Teológico san Ildefonso, Toledo.

FramiñÁn de Miguel, M. ${ }^{a}$ Jesús (2005), "Manuales para el adoctrinamiento de neoconversos en el siglo XVI”, Criticón, 93, pp. 25-37.

Gallego Burín, Antonio y Gámir Sandoval, Alfonso (1968), Los moriscos del reino de Granada según el Sínodo de Guadix de 1554, Universidad, Granada.

García-Arenal, Mercedes (1978), Inquisición y moriscos. Los procesos del Tribunal de Cuenca, Siglo XXI, Madrid.

García Pedraza, Amalia (2002), Actitudes ante la muerte en la Granada del siglo XVI. Los moriscos que quisieron salvarse, Universidad, Granada.

Gómez-Moreno Calera, José Manuel (1987), "La Catedral de Guadix en los siglos XVI y XVII", Cuadernos de Arte, 28, pp. 107-117.

GonzÁlez Torres, Javier (2003), "El tabernáculo: hito sacramental y referente espacial en las catedrales andaluzas", en G. Ramallo Asensio (coord.), El comportamiento de las catedrales españolas: del Barroco a los historicismos, Universidad, Murcia.

- (2016), La Capilla sacramental en el Barroco andaluz: espacio, simbolismo e iconografía (siglos XVI-XVIII), Universidad, Málaga. [file:///Users/javiergonzaleztorres/Downloads/TD_GONZALEZ_TORRES_Javier.pdf]

- (2017), "Las Constituciones sinodales andaluzas de los siglos XVI y XVII. Dimensión social y trascendencia historiográfica como fuente legislativa para el estudio del arte eucarístico", Norba. Revista de Arte, XXXVII, pp. 143-165. 
Guerrero, Pedro (1572), Constituciones synodales del Arçobispado de Granada, Casa de Hugo de Menu, Granada.

Hernández SÁnchez, Antonio (1955), Catecismos para la instrucción religiosa de los moriscos, Pontificia Universidad, Salamanca. Repositorio de la UPSA https://summa.upsa.es/pdf.vm?id=0000007799\&page $=1$ [consultado 16.08.2018]

Ladero Quesada, Miguel Ángel (1988), Granada después de la conquista: repobladores y mudéjares, Diputación Provincial, Granada.

López Arandia, M. ${ }^{a}$ Amparo (2007), Rinascimento y reformatio. El proyecto de Gutierre González en Jaén, Universidad, Jaén.

López-Guadalupe Muñoz, Miguel Luis (1996-1997), “Orden, gobierno y piedad. Hospitales de la diócesis de Granada en la segunda mitad del siglo XVIII", Revista del Centro de Estudios Históricos de Granada y su Reino, 10-11, pp. 299-328.

Marín Ocete, Antonio (1970), Don Pedro Guerrero, arzobispo de Granada (15461551), Universidad, Granada.

Mármol Carvajal, Luis del (1797), Historia del rebelión y castigo de los moriscos del Reyno de Granada..., t. I, Imprenta de Sancha, Madrid, 2. ${ }^{a}$ edición.

Martínez Peñas, Leandro y Herreros Cepeda, Alicia (2011), "El desplazamiento de los moriscos tras la rebelión de las Alpujarras: contexto político, estratégico y militar de una migración forzosa", en F. J. García Castaño y N. Kressova (coords.), Actas del I Congreso Internacional de migraciones en Andalucía, Granada, pp. 2073-2082.

Medina Rojas, Francisco (1988), "La Compañía de Jesús y la minoría morisca”, Archivum Historicum Societatis Iesu, LVII, 113, pp. 3-136.

Montoya Martínez, Jesús (2007), "Hernando de Talavera apologista, catequista y hagiógrafo", Revista del Centro de Estudios Históricos de Granada y su Reino, 19, pp. 47-65.

Pérez de Ayala, Martín (1556), Synodo de la diócesis de Guadix y de Baça, celebrado por el Reverendissimo Señor... Casa de Juan de Brócar, Alcalá de Henares. Edición facsímil con estudio previo de C. Asenjo Sedano (1994), Universidad, Granada.

- (1599), Catechismo para instrvccion de los nvevamente convertidos de moros. Impresso por orden del Patriarcha de Antiochia y Arçobispo de Valencia Don Iuan de Ribera, Pedro Patricio Mey, Valencia.

Quesada Morillas, Yolanda (2008), "Los moriscos del Reino de Granada: su expulsión y el consejo de población”, Revista electrónica de la Facultad de Derecho de la Universidad de Granada, pp. 1-27.

Ramírez de Villaescusa de Haro, Diego (¿1512?), Constituciones del Obispado de Málaga, Jacobo Cronberger, Sevilla.

Resines, Luis (2003), Catecismo del Sacromonte y Doctrina Christiana de fr. Pedro de Feria. Conversión y evangelización de moriscos e indios, col. Corpus Hispanorum de pace serie II, vol. 10, CSIC, Madrid. 
Río, Ana M. (2006), Los Mosqueteros del Santísimo Sacramento, Velocitynet, Granada.

Rosenthal, Earl E. (1990), La catedral de Granada. Un estudio sobre el Renacimiento español, Universidad, Granada.

Rojas y SANDOval, Cristóbal (1572), Sinodo diocesano del ilustrissimo y reverendissimo señor... Sevilla.

Sánchez López, Juan Antonio (1993), "Non Vos Delerinquam. La Catedral de Málaga y un sueño del Renacimiento", Espacio, Tiempo y Forma, Serie VII, 6, pp. 221-240.

- (1995), Historia de una utopía estética: el proyecto de Tabernáculo para la Catedral de Málaga, Universidad, Málaga.

Suberbiola Martínez, Jesús (1995), "La quema de iglesias en la tierra de VélezMálaga durante la rebelión morisca de 1568", Baetica. Estudios de Arte, Geografia e Historia, 17, pp. 335-355.

SuÁrez, Pedro (1696), Historia de el Obispado de Guadix y Baza. Imprenta de Antonio Román, Madrid.

Talavera, Hernando de (ca. 1500), Instrucción del arzobispo de Granada en respuesta a cierta petición que hicieron los vecinos del Albaicín. Texto íntegro recogido por T. de Azcona (1964), Isabel la Católica, BAC, Madrid.

Tejado y Ramiro, Juan (1863), Colección de cánones de todos los concilios de la Iglesia de España y América... Tomo V, Imprenta de Pedro Montero, Madrid.

Torre y del Cerro, Antonio de la (1913), Memorial de la vida de fray Francisco Jiménez de Cisneros, Centro de Estudios Históricos, Madrid.

Villegas, Alonso de (1589), Flos Sanctorum. Quarta y ultima parte, y discursos, ó sermones, sobre los Evangelios de todas las Dominicas del año..., Pedro Madrigal, Madrid. 